\title{
QUANTO VALE A ARTE CONTEMPORÂNEA?
}

\author{
TATIANA SAMPAiO FERRAZ
}

\section{RESUMO}

$\mathrm{O}$ artigo analisa o aquecimento do mercado de arte contemporânea nas últimas décadas no Brasil à luz das recentes transformações dos negócios, cada vez mais pautados pelo capital financeiro. No cenário de financeirização generalizada, é preciso repor o problema da natureza da arte - como mercadoria e como patrimônio cultural, oscilando entre o público e o privado.

PALAVRAS-ChaVE: arte contemporânea; mercado de arte; valor; renda monopolista.

\section{ABSTRACT}

The article analyzes the heating of the contemporary art market in the last decades in Brazil through the recent transformations of the business which is increasingly oriented by financial capital. In general financialization scenario, it is necessary to reset the problem of art - as a commodity and as a cultural heritage, oscillating between the public and the private.

KEYWORDS: contemporary art; art market; value; monopoly rent

[1] Este artigo não teria sido possível sem o debate ocorrido durante o curso Cidade e cultura: tensões contemporâneas em relação à arquitetura e à arte urbana, ministrado por Vera Pallamin e Luis Recaman, dentro do Programa de Pós-Graduação da FAU-USP, no primeiro semestre de 2014 .

[2] Moulin, Raymonde. Le marché de la peinture en France. Paris: Éditions de Minuit, 1967.

\section{TRANSFORMAÇÕES NOS MECANISMOS dE CIRCULAÇÃo ECONÔMICA DA ARTE CONTEMPORÂNEA E SUAS IMBRICAÇÕES NO CIRCUITO BRASILEIRO}

De acordo com o estudo sociológico de Raymond Moulin sobre o mercado de arte, publicado em $1967,{ }^{2}$ os negociantes de arte inserem $o$ artista na economia social transformando os valores estéticos em valores econômicos. Em termos práticos, isso implica a mobilização de outros agentes culturais legitimadores - instituições, museus, críticos de arte, curadores, historiadores, museólogos e especialistas da área em geral - que, junto com os negociantes, formam redes complexas de circulação de capital econômico e simbólico em torno da produção artística. 
Sabe-se que o mercado de arte não é algo novo - há mercados muito maduros, como são os casos dos Estados Unidos, da Inglaterra e da França-, porém o forte incremento nos negócios das últimas décadas chama atenção diante de um cenário de crise econômica mundial (do capitalismo tardio), prefigurada na bolha imobiliária norte-americana, com a consequente desestabilização do sistema bancário naquele país e seu efeito dominó no mundo. Além disso, as mudanças econômicas do capital global implicaram a entrada de novos protagonistas no mercado - como é o caso do gigante chinês (e o seu dinâmico mercado secundário) e da arte brasileira (e sua crescente internacionalização).

$\mathrm{O}$ artigo procura analisar as raízes do aquecimento do mercado de arte dos últimos anos num cenário global de crise - principalmente da produção contemporânea, e com especial interesse no Brasil -, à luz das recentes transformações dos negócios, cada vez mais pautados pela lógica do capital financeiro. Para tanto, recuperar o contexto dos anos 1970 parece ser fundamental; ali vimos o despertar do mercado de arte no Brasil, que coincidiu com o início dos processos de financeirização do capitalismo (criação de excedentes de capital fictício dentro do sistema bancário)3.

A financeirização da cultura e, por extensão, da arte é o cenário encontrado para se repor o problema da natureza do objeto artístico - como mercadoria (produto) e como patrimônio cultural (obra). O horizonte da arte se coloca na notória dialética entre o público e o privado. Na condição de mercadoria, a arte e suas características "especiais" possibilitam um incremento da exploração econômica que vai de encontro às mais recentes estratégias utilizadas pelo mercado de arte - o leilão, a feira e a galeria.

\section{O MERCADO: O INCREMENTO dOS NEGÓCIOS E A ARTE CONTEMPORÂNEA}

De modo geral, segundo o sociólogo Moulin, o mercado de arte se divide em três segmentos: o de "cromos" ou "quadros por dúzia", que geralmente são obras de caráter figurativo, respondem aos imperativos do gosto majoritário e aproximam-se dos bens correntes de consumo, não artísticos; o de arte "antiga", cujos valores estéticos e financeiros estão mais que estabilizados e cujas razões para flutuações residem no campo da autenticação e da expertise; e o de arte "contemporânea", caracterizado pelas incertezas quanto aos valores estético e financeiro ${ }^{4}$. Sendo essas últimas investimentos de alto risco, implicam, por sua vez, altos lucros.

$\mathrm{O}$ crescente interesse pela arte contemporânea pode ser mensurado pelas vendas do mercado internacional nos últimos anos. De acordo com o relatório encomendado pela European Fine Art Foundation
[3] Harvey, David. Oenigma do capital $e$ as crises do capitalismo. São Paulo: Boitempo, 2011, p. 33 .

\footnotetext{
[4] Raymonde Moulin. "Evolução do mercado de arte: internacionalização crescente e desenvolvimento da arte contemporânea". In: Quemin, Alain (org.). O valor da obra de arte. São Paulo: Metalivros, 2014, p. 12.
} 
[5] The European Fine Art Fair, realizada em Maastricht, é a feira mais cobiçada do mundo; possui diversas restrições quanto à participação das galerias, chegando a ter inspetores que fazem a aprovação final das obras expostas nos estandes um dia antes da abertura do evento.

[6] Fialho, Ana Letícia (coord.). Pesquisa setorial: o mercado de arte contemporânea no Brasil. 3. ed. São Paulo: Latitude/Abact, 2014.

[7] TEFAF Art Market Report 2013. <http://www.cinoa.org/public/TEFAF_AMR_2013-_KEY_FINDINGS.pdf>

[8] Harvey, David. "A crise". In: $O$ enigma do capital, op. cit., pp. 9-40.

[9] Cypriano, Fabio. "Brasil representa $1 \%$ do mercado global". Folha de S.Paulo, 16/3/2013. <http://www1.folha.uol.com.br/ilustrada/1247054-brasil-representa-so-1-do-mercado-de-arte.shtml> (que promove a Tefafs), publicado em $2013,43 \%$ das transações globais de obras de arte feitas em leilões no ano anterior correspondem à arte contemporânea, seguidas por $30 \%$ de vendas de exemplares modernos. No Brasil, os resultados da pesquisa setorial Latitude 2014, realizada pela Abact (Associação Brasileira de Arte Contemporânea) indicaram um aumento do percentual de artistas que entraram pela primeira vez no mercado em 2013 em relação ao ano anterior ${ }^{6}$.

A pesquisa da Tefaf destaca que o aumento da riqueza per capita e, em especial, do número de HNWIs (high-net-worth individual - definidos como aqueles que possuem alto poder de investimento financeiro, superior a 1 milhão de dólares) levou proporcionalmente ao maior consumo de bens de luxo, aí incluída a arte7. O que explicaria, por sua vez, o fenômeno HNWI? O paralelo entre as razões que atraíram os investidores para o mercado de arte e a expansão do mercado de ativos é inevitável.

As análises de David Harvey acerca da crise do capitalismo em 2007 mostram que os investimentos da classe rentista nas últimas décadas foram deslocados de uma instância real em direção a uma abstração ${ }^{8}$. No período conhecido como pós-modernidade, o excedente do capital industrial, que antes era reinvestido nas suas próprias empresas, é deslocado para o mercado de ativos, que oferece maiores lucros e de forma mais rápida. Assim, os investimentos de alto risco na bolsa de valores transformaram bens materiais em papéis. O mercado de arte também atraiu esse excedente, uma vez que a sua mercadoria, tão especial, se mostrou um negócio altamente rentável.

No relatório europeu de 2013, os economistas dedicaram-se a estudar os mercados emergentes, inclusive os países do BRIC (e pela primeira vez o Brasil), que apresentaram uma melhor reação aos momentos de crise do que os mercados "maduros". O Brasil obteve $1 \%$ das trocas globais, enquanto a China movimentou $27 \%$ do mercado. No ranking mundial, Nova York e Londres lideraram as transações do mercado de arte, somando $64 \%$ das importações e $62 \%$ das exportações, respectivamente.

Segundo a economista Clare McAndrew (à frente da pesquisa no Brasil), apesar do poder de compra expressivo dado pelo aumento de colecionadores ricos locais - que, por sua vez, explica o aumento da participação do país no mercado global -, o Brasil ainda engatinha no desenvolvimento dos negócios, se comparado ao "bric" chinês9. Para os negociantes, um dos principais entraves são os altos impostos de importação e exportação. Para a economista, outro sinal é a pouca expressividade do mercado secundário no balanço final. Se a China movimenta $70 \%$ das suas transações em leilões, aqui as casas de leilão representam apenas $21 \%$ das vendas. A liquidez do mercado chinês é bem superior, a ponto de obras chegarem a circular quatro vezes no 
mercado em menos de dez anos. Não à toa, o mercado de falsificações vem crescendo enormemente na China, chegando à bizarrice de artistas falsificarem suas próprias obras ${ }^{10}$. O que significa, então, medir os índices de desenvolvimento do mercado de arte hoje pela alta liquidez de obras comercializadas nas casas leiloeiras?

\subsection{Os leilões}

O leilão parece ser a representação perse do modus operandi do mercado no seu atual estágio - movido pela lógica do capital financeiro. A sequência de lances, desde o valor de referência ${ }^{11}$ anunciado pelo leiloeiro no início do pregão, é o fascínio do jogo especulativo, e pode atingir preços nunca antes imaginados. O elemento "agora ou nunca", presente na atividade leiloeira, alimenta ainda mais a disputa durante o pregão.

$\mathrm{Na}$ arte, o grau de exclusividade dá o tom das oportunidades de negócio, algo que Harvey notou igualmente no mercado internacional de vinhos - a exemplo do terroir francês ${ }^{12}$. Tal como o mercado de arte, o comércio de vinhos se apoia no seu caráter "especial" a fim de obter vantagens rentistas na venda de seus produtos.

Além do caráter exclusivista, próprio da qualidade da obra de arte, o economista Don Thompson levantou diversas estratégias utilizadas para valorizar o valor das obras nos leilões, cuja pesquisa foi publicada no livro $O$ tubarão de 12 milhões de dólares, em $2008^{13}$. Um dos exemplos apontados é a representação de um colecionador bilionário (geralmente russo ou chinês) por um negociantelocal,em que este dá altos lances para a obra de um artista a fim de valorizar a coleção pessoal do representado (que, desse modo, preserva seu anonimato). Da mesma forma, marchands também dão lances em artistas que eles próprios representam, e tal valorização induz ao aumento dos preços em outras vendas do mesmo artista - é o que eles chamam de "proteção do estoque"14.

2008 é o ano do célebre leilão de peças de Damien Hirst, na casa londrina Sotheby's, onde o artista pôs 223 trabalhos à venda, subvertendo a própria ideia do mercado secundário ao prescindir de consignatários e, desse modo, expondo a artificialidade da estrutura vigente. A estratégia de Hirst foi concebida como uma "performance", comenta Cildo Meireles em entrevista concedida a Angélica de Moraes. Cildo lembra que, ironicamente, o artista embolsou rios de dinheiro um ano antes de o banco norte-americano Lehman Brothers quebrar ${ }^{15}$. Tal como o colecionador e o marchand, aqui o artista tratou de especular com suas obras ao pedir a amigos que dessem altos lances no primeiro dia, criando um fervor competitivo e contribuindo para a bolha especulativa de seus "ativos".
[10] Padilla, Ivan. "Qual o valor da arte?”. Época Negócios. <http://epocanegocios. globo.com/Revista/Common/o,,ERT125293-16642,00. html>

[11] O valor de referência geralmente é estabelecido em $60 \%$ do valor estimado da obra.

[12] Harvey, David. "A arte da renda: a globalização e transformação da cultura em commodities". In: A produção capitalista do espaço. São Paulo: Annablume, 2005, pp. 221-39.

[13] Thompson, Don. O tubarão de 12 milhões de dólares: a curiosa economia da arte contemporânea. São Paulo: BEI, 2012.

[14] Thompson, op. cit., p. 197.

[15] Moraes, Angélica de. "Criação de valor". In: Quemin, Alain (org.), op. cit., p. 108. 
[16] A sigla UHNW significa ultra high net worth, conhecidos vulgarmente como os multimilionários.

[17] Para conhecer exemplos concretos desse mecanismo, verThompson, op. cit., pp. 153-173.

[18] Thompson, op. cit., pp. 240-241.

[19] Thompson, op. cit., p. 232.
"Isso é negócio, não história da arte", esclarece Brett Gorvy, presidente e representante de arte contemporânea da Christie's. Nos últimos anos, as casas de leilão dedicaram-se a incrementar o aparato comercial pré-leilão. Impressão de catálogos de primeira linha, dúzias de jantares para angariar comitentes e licitantes promissores (especialmente colecionadores de patrimônio líquido ultraelevado, os $\mathrm{UHNW}^{16}$ ), encontros restritos com os especialistas das casas, mostras com sofisticado arranjo expositivo, entre outras estratégias ${ }^{17}$. Além disso, os especialistas das casas de leilão tornaram-se profissionais de marketing, analisam o comportamento de compra de um colecionador como sinal de sua aspiração a determinado grupo social. Uma das fontes de obras mais procuradas para alimentar os pregões, relata Thompson, são os grandes espólios, na esperança de renderem oportunidades exclusivas de venda.

A relação entre leilões e marchands parece complexa, ambos procuram criar novas condições privilegiadas de compra e venda e meios de potencializar o valor da obra à venda. Mas, ao mesmo tempo em que disputam a mesma clientela, os negócios dos mercados primário e secundário se retroalimentam. A pesquisa de Thompson indica que 30\% das consignações das principais casas de leilão - Christie's, Sotheby's e Phillips de Pury - são provenientes de marchands. E vai além, algumas casas de leilão chegam a adquirir galerias a fim de atuar simultaneamente no mercado primário. É o caso da Christie's, que adquiriu a Haunch of Venison em 2007, abrindo uma filial no vigésimo andar do Rockfeller Center ${ }^{18}$.

Se os marchands, de um lado, reclamam de que "as casas são promotoras comerciais ricas que só querem saber do valor e de seus clientes, sem se preocupar com os artistas", de outro, os leiloeiros respondem que "o papel deles é aproximar comprador e vendedor, e assim promover o artista"19. De todo modo, fica a impressão de que no mundo dos leilões a voracidade do business é maior.

\subsection{As feiras de arte}

Diante do fascínio do jogo dos pregões e do aporte financeiro das casas leiloeiras, as feiras internacionais se mostraram uma ótima vantagem competitiva para os galeristas. Elas são capazes de atrair um grande número de colecionadores a um único local arranjo eficiente, se lembrarmos que o grande alvo dos negócios são os milionários, que, embora tenham muito dinheiro, dispõem de pouco tempo.

Apesar de existirem desde as exposições universais de Paris, na era da globalização, as feiras internacionais se desenvolveram como um dos modos mais eficazes de aumentar as vendas das galerias - passaram de 55, em 2001, para 205 feiras, em 2008. No Brasil, o relatório 
Latitude 2014 mostra que as feiras cumprem um papel muito importante para as galerias nacionais: somam $40 \%$ das vendas ${ }^{20}$. No mesmo levantamento, $56 \%$ das galerias nacionais declararam que a SPArte foi a feira mais rentável em termos de negócio.

Dentre as 205 feiras existentes no mundo, há nichos de mercado de diversas escalas, sendo as feiras mais "expressivas" em números absolutos de venda a Tefaf (Maastricht), seguida de Art Basel, Frieze (Londres), Armory Show (Nova York) e Art Basel Miami. A pesquisa de Thompson relevou que a participação nas cinco feiras pode significar um gasto anual de 300 mil libras para a galeria; porém, se o marchand não arcar com os custos, pode parecer que a feira não o aceitou, o que o levaria a perder sua credibilidade no mercado ${ }^{21}$.

Tal como as casas de leilão, as feiras desenvolvem seus próprios mecanismos sofisticados para incrementar seus negócios, desde a precificação do ingresso no evento - que pode aumentar quanto mais cedo o colecionador chegar ao evento e, assim, dispor das primeiras oportunidades de compra - até a exclusividade de acesso concebida para certos colecionadores do chamado UHNW antes mesmo da abertura do evento.

De modo geral, o incremento das vendas nas feiras representa uma mudança cultural na compra de arte, pois substitui as compras individualizadas - espacial e temporalmente - nas galerias pelo frenesi do vai e vem do público no evento. Em um único local, os estandes devenda das galerias oferecem com segurança o que há de mais "novo". Além da praticidade, a feira significa um alto grau de conforto em termos de risco, uma vez que a simples quantidade de pessoas e de etiquetas "vendido" diminui as incertezas do comprador. É o que Thompson identifica como psicologia de rebanho: "[...] quando um colecionador não dispõe de informações suficientes para tomar uma decisão racional, ele se sente tranquilizado imitando o comportamento do rebanho" 22. Comportamento semelhante se faz notar no mercado financeiro, com o uso do termo "bullish" para designar as ondas de compra induzidas - a figura do "touro" de Wall Street.

As feiras têm se tornado o meio mais importante para conhecer o que os artistas contemporâneos estão produzindo - mais do que curadorias feitas em galerias, museus e centros culturais. Tanto é verdade que somente $15 \%$ das vendas são feitas a instituições, nacionais e internacionais, o que colabora ainda mais para a privatização da arte - se você não for a uma feira, a oportunidade de rever uma obra vendida no evento é quase nula, a não ser no caso de alguns poucos colecionadores que têm consciência da dimensão pública de seus acervos privados. (Cabe citar aqui a posição singular do artista Eduardo Berliner, que só autoriza a venda de suas obras pela galeria depois de terem sido expostas publicamente).
[20] Fialho, op. cit., p. 27.

[21] Thompson, op. cit., p. 251.

[22] Thompson, op. cit., p. 250. 
[23] Moraes, Angélica de. "O fiel depositário". In: Quemin, Alain (org.), op. cit., p. 204.
No Brasil, parece sintomático que a maior feira de arte ocorra no mesmo edifício histórico que a Bienal. Em 2013, a SpArte teve recorde de público em relação aos anos anteriores, com 22.500 visitantes pagantes durante cinco dias (4.50o por dia). Comparativamente, a última edição da Bienal, em 2012, teve 520 mil visitantes não pagantes, com média diária de 5.500 .

\subsection{As galerias}

Comprar em leilões e feiras se tornou um hábito para os investidores; as vendas em galerias parecem ter se restringido aos amantes da arte. O depoimento de João Carlos de Figueiredo Ferraz concedido a Angélica de Moraes exemplifica a diferença de comportamento: o colecionador prefere ver exposições nas galerias e se deixar "enamorar" por uma obra até decidir adquiri-la para sua coleção. Aos olhos de Ferraz, o mercado da arte não pode se restringir a investimentos. Para ele, sua coleção tem um valor inestimável, "é um valor cultural, é um patrimônio da humanidade, que vai muito além dessa ideia quantitativa do valor patrimonial" 23 .

Uma mudança de perfil também pode ser notada do outro lado dos negócios. Grosso modo, em São Paulo, a partir dos anos 2000 , boa parte dos novos marchands são homens provenientes do mercado financeiro (afinal, a bolsa de valores é um universo essencialmente masculino), enquanto diversas galerias importantes criadas entre os anos 1970 e 1980 têm por trás mulheres, as quais, no início, trabalhavam (afetivamente) motivadas a ajudar os amigos artistas a venderem suas obras.

De todo modo, as galerias não ficam longe nas estratégias de mercado para o incremento da valorização do valor da obra. Duas histórias ilustram os mecanismos distorcidos da precificação de um trabalho de arte: a primeira trata da escolha do colecionador "certo" para uma determinada obra (ora, se um marchand se recusa a vender uma obra porque fulano não é digno daquele objeto estético, o desejo por esteé ainda mais fetichizado e o preço aumenta); a segunda se dá pelo controle da produção de um determinado tipo de trabalho que já se mostrou rentável ao mercado (é necessário controlar a venda da produção por meio da limitação de obras em circulação e da criação de "listas de espera", o que não significa necessariamente que o artista tenha vendido todas as obras, mas que o marchand deve torná-las ainda mais cobiçadas a fim de valorizá-las). 


\subsection{O caso brasileiro}

Uma das conclusões a que chegou a pesquisa Latitude $2014^{24}$ no Brasil foi "o crescente número de galerias que o circuito de arte tem absorvido nas últimas décadas, de 2 novas galerias na década de 1970 para 15, em 2010". Das 45 galerias pesquisadas, $30 \%$ foram criadas na década de 2000 ; destas, $33 \%$ depois de 2010 . Grosso modo, a "evolução" do mercado de arte no país desde os anos $1970^{25}$ equivale ao processo de profissionalização do meio, que se desenvolveu igualmente paripassu com as mudanças econômicas na geografia mundial do capital (a virada da financeirização).

O pós-guerra forçou o início da profissionalização do mercado de arte brasileiro, por meio das atividades de imigrantes recém-chegados ao país, tais como Giuseppe Baccaro, Arturo Profilli, Franco Terranova, Jean Boghici e Pietro Maria Bardi. Surgiram as primeiras galerias a representar arte moderna - Azkanazy, no Rio de Janeiro, e Domus, em São Paulo. Os anos seguintes foram mobilizados pela criação de grandes museus - Museu de Arte de São Paulo Assis Chateaubriand, Museu de Arte Moderna do Rio de Janeiro e Museu de Arte Moderna de São Paulo. As primeiras bienais colaboraram igualmente para o fomento da produção artística, das trocas internacionais e dos negócios locais.

Mas é somente nos anos 1970 que o mercado de arte passa a crescer de fato. $O$ pano de fundo no Brasil era tomado pela ditadura e pelo "milagre econômico". Um dos protagonistas desse crescimento é José Paulo Domingues da Silva ${ }^{26}$, dono da Galeria Collectio, que promoveu os primeiros leilões na cidade de São Paulo. A galeria tinha como seu credor o Banco Áurea de Investimentos, por meio do qual emprestava dinheiro a seus próprios clientes. Em 1973, suas ousadias financeiras acabaram - o banco declarou falência e a galeria fechou as portas ${ }^{27}$.

O conhecido boom dos anos 1980 tem por trás a explosão da pintura no país. A jovem geração de pintores, tais como os do grupo Casa 7 , desde muito cedo participa das bienais de São Paulo. As razões do crescimento desse mercado também podem ser apontadas na própria qualidade singular da pintura - que mantém sua aura de obra única até hoje. Como tal, ela se mostra a expressão artística preferida entre os compradores do mercado de arte. Na última pesquisa Latitude, liderou as vendas nacionais em $24 \%$, seguida por $23 \%$ de fotografias, $19 \%$ de esculturas, $11 \%$ de desenhos ${ }^{28}$.

A internacionalização do mercado de arte brasileira acelerou-se a partir da década de 1990, com o incremento dos mecanismos de intercâmbio de artistas por meio de programas de residência, o aumento da participação das galerias em feiras internacionais e a expansão das fronteiras da Bienal de São Paulo - em especial, da $24^{\text {a }}$ Bienal, com curadoria de Paulo Herkenhoff, que pela primeira vez atraiu um grande número de colecionadores estrangeiros ${ }^{29}$.
[24] Gonçalves Filho, Antônio. "Galerias já vendem mais obras para as instituições de fora". O Estado de $S$. Paulo, Cultura, 31/3/2014. 〈http:// www.estadao.com.br/noticias/ impresso,galerias-ja-vendem-mais-obras-para-as-instituicoes-de-fora,1147260,o.htm>

[25] Sobre o histórico das galerias de arte no Brasil ver Fioravante, Celso. "O marchand, o artista, o mercado". Forum Permanente, 2001. 〈http://www.forumpermanente.org/event_pres/exposicoes/ arte-contemporaneo-arco/artigos-relacionados/o-marchand-o-artista-e-o-mercado>

[26] Seu nome verdadeiro era Paulo Businco, um italiano estelionatário procurado pela Interpol.

[27] Rodrigues, Rachel Vallego. "Transitoriedades: uma coleção, diversos museus". In: Monteiro, R. H.e Rocha, C. (orgs.).Anais do VI Seminário Nacional de Pesquisa em Arte e Cultura Visual. Goiânia: UFG/FAV, 2013. <http://www.fav.ufg.br/seminariodeculturavisual/Arquivos/2013/034-eixol.pdf>

[28] Fialho, op. cit., p. 28.

[29] Ver depoimento da galerista Luisa Strina sobre a $24^{\text {a }}$ edição da Bienal Internacional de São Paulo em Moraes, Angélica de. "Expansão de valor". In: Quemin, Alain (org.), op. cit., p. 224. 
[30] Quemin, op. cit., p. 13.

[31] Fialho, op. cit., p. 29.

[32] Fialho, Ana Letícia. "Expansão do mercado de arte no Brasil: oportunidades e desafios". In: Quemin, Alain (org.), op. cit., p. 33 .
Há quem diga que o momento atual do mercado de arte é preocupante. Depoimentos de alguns dos maiores galeristas paulistas por ocasião da SPArte em 2014 relatam o desmanche de marchands que iniciaram suas atividades na última década e que não conseguiram manter suas portas abertas. Fica a pergunta: será que existe espaço para os amadores no grande round do atual capitalismo? Na escala econômica global, isso parece ir de encontro à lei dos mais fortes, das fusões e incorporações. Sabe-se que a chamada competitividade saudável do mercado apregoada nos primórdios do capitalismo industrial culmina hoje na era dos grandes conglomerados.

\section{ARTE COMO MERCADORIA}

O sociólogo Quemin recorre às análises de Raymond Moulin (1992) sobre o mercado de arte na França nos anos 1980 para demonstrar que o valor da arte se constitui a partir da articulação entre o mercado e o museu - a valorização de mercado e a valorização estética - que se apoiam uma sobre a outra. "A certificação do valor estético condiciona o preço, ainda que o preço seja, por sua vez, um dos critérios de certificação do valor estético"30.

O relatório Latitude esclarece que, apesar de os números relativos a aquisições de colecionadores particulares serem maciçamente superiores em 2014, se comparados às vendas para instituições, nacionaise internacionais (que somaram apenas $15 \%$ das transações), a pequena participação dos museus é fundamental para atribuir valor à obra ${ }^{31}$.

Para Ana Letícia Fialho, os processos de formação do valor de uma obra de arte são ainda mais complexos, envolvendo pelo menos quatro instâncias fundamentais, cujas dinâmicas são distintas mas interrelacionadas: produção, reflexão crítica, institucional e merca$\mathrm{do}^{32}$. Em nota, Fialho alerta para o fato de que a proporção entre as quatro instâncias é variável: em sistemas de arte consolidados, há um equilíbrio entre elas, e todas ajudam a fomentar a produção; em sistemas menos consolidados, há uma desproporção entre as partes, e muitas vezes, como é o caso do Brasil, o mercado assume função preponderante na definição do valor diante da fragilidade institucional do circuito.

Atualmente, há diversos indicadores internacionais publicados na plataforma da internet que atualizam permanentemente índices de preços e valores de obras de arte, tais como Artnet, Artprice, Artfacts e o brasileiro Catálogo das Artes. Em geral, os índices são medidos pelos lances no mercado secundário. A sofisticação da formação do valor da arte como mercadoria e o crescente interesse do mercado pela produção contemporânea não escapam ao entendimento de que fazem parte dos processos recentes de "financeirização da cultura". 
A economia global nos ensina que o crescente mercado de arte não se deu pelo aumento do gosto pela arte - nem por parte dos colecionadores, nem por parte dos galeristas (lembrando que um contingente significativo de novos dealers paulistanos veio do mercado financeiro), mas pelos altos lucros a curto prazo. O exemplo paradigmático é o fenômeno Milhazes: a artista que teve uma obra vendida em 2001 e leiloada em 2008 cuja valorização alcançou $6.000 \% 33$.

Como bem durável, diferentemente de outras commodities, a arte permite que quem nela invista não corra o risco de ter seu patrimônio desvalorizado. São raras as depreciações de valor. Como diz Thompson, "Quando o martelo bate, o preço se transforma em valor e este se inscreve na história da arte"34. A arte vira um bem altamente rentável; por ter alta liquidez, passa a circular dentro da lógica do mercado de ações, cujos mecanismos são regulados tão somente pela lei de oferta e procura.

Constatados os mecanismos de financeirização, faz-se necessário entender as especificidades da arte como mercadoria e como elas determinam um modo singular de transação comercial, potencializado na era do capital fictício. Sabemos que a mercadoria possui um duplo caráter, como valor de uso e como valor de troca. Um objeto só se torna mercadoria quando se insere no circuito das trocas. O mesmo acontece com o objeto de arte. Conforme observa Svetlana Alpers, "a obra [de arte] não tem nenhum uso prático a não ser como meio de estoque de valor e como expressão do valor na sua função de troca; é um valor criado ao repassá-lo;é, por assim dizer, uma valor partilhado"35.

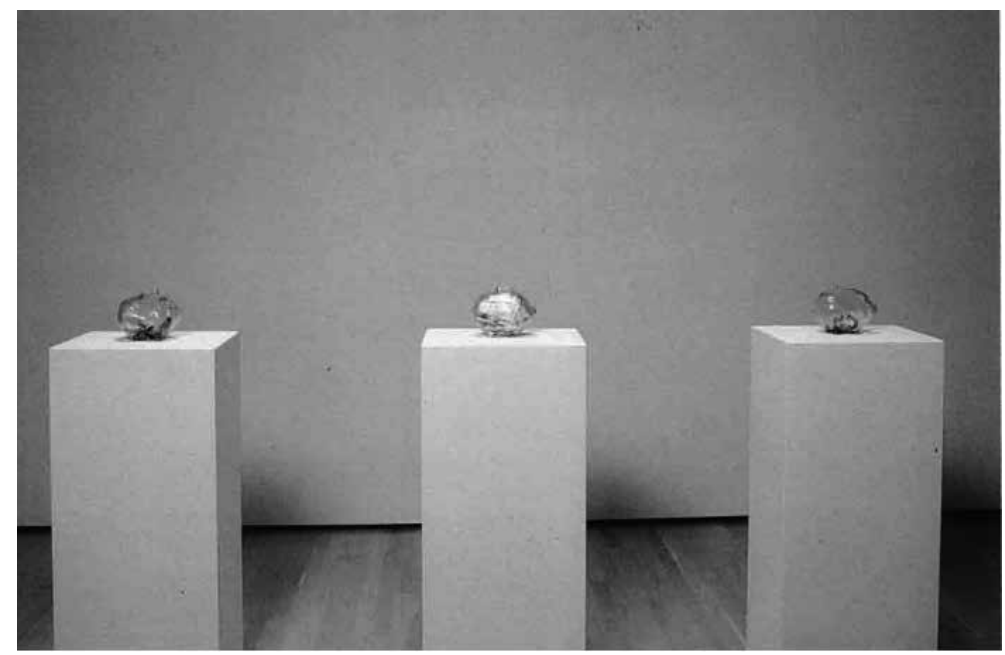

Cildo Meirelles. Eppursi muove, 1991. Foto: Wilton Montenegro.

Um dos artistas que mais exploram a noção de valor na arteé Cildo Meireles. Exemplos não faltam:Árvore do dinheiro (1969), Projeto cé-
[33] Padilla, op. cit.

[34] Thompson, op. cit., p. 260.

[35] Svetlana Alpers apud Moraes, Angélica de. "Valorações do transitório". In: Quemin, Alain (org.), op. cit., p. 90. 
[36] Moraes, Angélica de. "Criação de valor", op. cit., p. 104.

[37] Ver Jappe, Anselm. "A mercadoria, essa desconhecida". In:Asaventuras da mercadoria: para uma nova crítica do valor. Lisboa: Antígona, 2006.

[38] Harvey, David. "A arte da renda", op. cit., p. 221.

[39] Idem, p. 222. dulas da série Inserções em circuitos ideológicos (1970), Zero dollar (1978), para ficar na década de 1970. O trabalho que mais esgarçou a fantasmática do valor e, em especial, do dinheiro parece ter sido Eppursi muove (1991), comissionado para a exposição inaugural do Museu de Arte Contemporânea de Montreal, Pour la suite du monde. O artista usou a verba de produção da obra (US \$ 1.00o) para efetuar 150 operações de câmbio - trocou por dólares canadenses, libras, francos e assim sucessivamente. Ao final restaram apenas $\mathrm{CA} \$ 4$ em espéciee algumas moedas. Na exposição, Cildo apresentou três cofrinhos transparentes (em forma de porquinho) - no primeiro, os recibos do valor inicial; no segundo, as notas e moedas que tinham restado; e no terceiro, a mesma quantia como simulacro do troco dessas transações ${ }^{36}$.

Ao revisitar os mistérios da mercadoria, Anselm Jappe indica que o valor tornou-se uma forma de mediação social (é puramente social), é a forma fetichizada do trabalho37. O dinheiro, por conseguinte, seria a forma visível do valor, uma abstração real. Nos leilões, o preço não tem mais nada a ver com o valor, é o deslocamento total e cada vez maior e representa a maioria das relações econômicas a partir dos anos 1980, financeirizadas. Como vimos, o excedente dos mais ricos passa a ser investido em ativos, capital cultural (como o surgimento de novos museus e a expansão de grifes museais e bienais de arte mundo afora) e mercado de arte.

\subsection{Uma mercadoria tão especial...}

"Como a condição de mercadoria de tantos fenômenos culturais se harmoniza com o seu caráter específico?" 38 Harvey contribui para desvendar os mistérios da mercadoria "arte" por meio de suas análises sobre a relação cultura e capital tecidas à luz do caráter muito "especial" da primeira. Segundo o autor, a cultura diferencia-se das mercadorias "normais" por sua qualidade especial, ela seria o plano mais elevado da criatividade e do sentido humano.

A economia da cultura teria, assim, se beneficiado do caráter especial de sua mercadoria para extrair os maiores lucros possíveis. A operação, segundo Harvey, se dá por meio da obtenção de renda monopolista.

A renda monopolista surge porque os atores sociais podem aumentarseu fluxo de renda pormuito tempo, em virtude do controle exclusivo de um item, direta ou indiretamente, comercializável, que é, em alguns aspectos, crucial, único e irreplicável39.

Acategoria abstrata da renda monopolista, usada na economia política para cálculos financeiros, ajuda a entender analogamente como o vinho e a obra de arte tendem a ser cada vez mais valorizados pela sua 
singularidade. O leilão, por exemplo, tem o poder de fazer uma obra voltar ao mercado diversas vezes, e a cada vez especular sobre seu preço monopolista.

A contradição reside em que uma obra não pode ser tão especial assim a ponto de não poder ser precificada - mesmo que seu valor estimado seja assombroso, o mercado precisa garantir que haverá sempre meia dúzia de possíveis compradores para um autêntico Rafael. Uma segunda contradição é que necessariamente o mercado precisa ser competitivo e, portanto, precisa estimular suas negociações; ocorre que, quanto mais facilmente negociáveis se tornam os produtos, menos únicos e especiais eles são, o que significa dizer que menos eles proporcionam a base para a renda monopolista ${ }^{40}$.

A unicidade da obra de arte é extremamente controlada pelos artistas e por quem os representa no mercado - mesmo que a técnica empregada no trabalho de arte seja reprodutível, como é o caso da gravura, da fotografia, do vídeo e até mesmo da instalação. Na entrevista de Cildo supracitada, o artista conta que quando resolveu começar a vendar suas instalações, nos anos 1990, ele passou a fazer uma tiragem de três exemplares para cada uma. Em conversa informal com Marilá Dardot, a artista relatou que, apesar de ter produzido uma série de múltiplos para uma galeria, constatou que os colecionadores preferem comprar obras únicas, em vez de investir R $\$ 500$ em um múltiplo. O que reforça a tese da criadora do Multiplique Boutique, Gabriela Inui, de que a venda de múltiplos não tem um retorno financeiro significativo, mas serve como instrumento para divulgar o trabalho em outros nichos de mercado, para outros públicos, não necessariamente colecionadores investidores, mas para potenciais formadores de opinião.A unicidade também é um atributo requisitado pelo colecionador que deixou de adquirir uma escultura de Tunga porque há cinco cópias dela (segundo ele, só a compraria se a tiragem fosse de três exemplares, não importando aqui o aumento do preço).

\subsection{A arte entre o público e o privado}

Toda renda se baseia no poder monopolista da propriedade privada.A condição do objeto de arte como propriedade privada não escapa, assim, do caráter dialético do estatuto da arte como mercadoria. Como fazer conviver em harmonia a propriedade privada de uma obra, do ponto de vista do colecionador, e sua dimensão pública, pressuposta na atividade do artista ao conceber o trabalho para ser visto ad infinitum (como patrimônio cultural)?

A complexa condição da obra de arte - como mercadoria (propriedade privada) e como patrimônio cultural - é ainda mais estressada quando o colecionador particular se sente no direito, como proprietário daquele bem, de alterar o trabalho a seu bel-prazer.Até que ponto o
[40] Harvey cita, por exemplo, o desapontamento de um turista ao visitar a Eurodisney: "Na Disney alguma coisa sempre acontece, $\mathrm{e}$ as pessoas ficam felizes". Harvey, David. "A arte da renda", op. cit., p. 223. 
[41] Muito pouco se sabe sobre essas relações contratuais; o tema mereceria uma pesquisa mais específica, com depoimentos dos agentes culturais envolvidos, tarefa difícil de lograr no métier artístico atual.

[42] 〈http://www.museus.gov.br/ decreto-8-12413/>

[43] Rivitti, Thaís. "Escalas: o muito e o pouco na arte brasileira". 〈http:// thaisrivitti.com/2014/O4/O2/escalas-o-muito-e-o-pouco-no-mundo-da-arte/> colecionador pode fazer o que bem quiser com a obra? Teria ele o direito, enquanto "dono" daquela mercadoria, de destruí-la? Sabe-se que há casos em que obras de arte, principalmente de caráter instalativo, são alteradas sem constrangimento por parte de seus proprietários, em detrimento de uma certa adequação aos recintos onde são instaladas. Caberia, assim, aos artistas e dealers buscar estabelecer, quando necessário, certos contornos para esses "usos" da obra, e garantir sua dimensão pública4. (Vale relembrar aqui a saída criativa de Berliner para o problema da dimensão pública.)

Raiz do mesmo problema aparece no polêmico decreto 8.124/13 do Ibram (Instituto Brasileiro de Museus)42, publicado em 2013, no qual é sugerido que obras de coleções privadas possam ser designadas pelo Estado como de interesse público, e, nesse caso, proibidas de ser comercializadas no exterior. A ideia por trás disso é evitar a evasão de obras e coleções importantes para a história da arte brasileira - tal como se viu com o Abaporu, de Tarsila do Amaral, e a coleção de arte concreta e neoconcreta de Adolfo Leirner.

A dialética público-privado se alastra em diversas instâncias do circuito da arte atual. Em abril de 2014, por ocasião da SPArte, a crítica Thais Rivitti publicou o artigo "Escalas: o muito e o pouco na arte brasileira", onde expressa seu inconformismo quanto às relações distorcidas entre a esfera pública e o mundo privado que vêm sendo desenhadas no circuito da arte no Brasil43. Nesse caso, o MinC teria investido na feira de arte mediante renúncia fiscal de $\mathrm{R} \$ 2$ milhões, montante que equivaleria a $30 \%$ dos gastos para o evento de cinco dias.

Ora, se a arte é um investimento rentável, por que será que o mercado de arte tem de ser financiado com dinheiro público? A pergunta que está por trás vem a seguir: será que existe alguma instância ou ocorrência no mundo globalizado em que a circulação de mercadoria se dá livremente, sem a intervenção do Estado? O mercado imobiliário norte-americano nos mostrou que não, nem mesmo o grande protagonista do jogo capitalista foi capaz de se autorregular, e seus maiores bancos tiveram de ser socorridos pelo governo. Algo semelhante se passa no caso da ajuda financeira do $\mathrm{MinC}$ para a realização da SPArte.

O cenário deixa claro que o mercado (ainda hoje, por mais sofisticado que seja o desenvolvimento da circulação capitalista de mercadoria) não consegue se autorregular. Nem o mercado de arte seria "puramente" autorregulador. Mais adiante vem outra indagação: se o poder público é coautor desse mercado por meio do fomento às negociações da circulação de obras de arte, como ele desfruta de sua rentabilidade ao final?

Os investimentos públicos no fomento ao mercado de arte no país parecem somar porções muito pequenas dentro do grande caldo das 
negociações do mercado primário e secundário da arte. Haveria uma reversão sob a forma de tributação? Está por ser feita uma pesquisa aprofundada sobre a regulamentação do mercado de arte, que busque entender por meio de dados estatísticos se há retorno dos investimentos públicos na forma de imposto, seja ele pago pela galeria que vende, seja pela declaração de IR dos colecionadores.

Por outro lado, o governo também é parte do jogo econômico das trocas simbólicas, e nesse sentido tem interesses políticos em tomar parte em um evento que está inserido no mercado global. A feira acaba sendo mais uma estratégia para transformar a imagem da cidade (e do país, por extensão) em um polo de interesse econômico na geografia do capitalismo global.

De volta ao texto de Rivitti, o desequilíbrio dos investimentos públicos nos diversos sistemas da arte no país, das mais variadas escalas, faz pensar no que parece ser o problema central: como equalizar os investimentos via leis de fomento, e de políticas públicas para a arte em geral, direcionados aos grandes eventos, aos acervos públicos e de interesse público (a exemplo do Masp) e a microempreendedores?

O quadro se agrava ainda mais se considerarmos que o Brasil vive uma situação paradoxal: ao mesmo tempo em que o mercado de arte se mostra vigorosamente em expansão, alicerçado sobre uma produção profícua que se internacionaliza cada vez mais, as instituições em geral se mostram frágeis, com poucos recursos humanos (gestores e políticas de gestão) e escassos aportes financeiros (principalmente, do ponto de vista das aquisições), mostrando-se pouco capazes de fomentar, exibir, refletire, sobretudo, colecionar a produção contemporânea.

Nesse sentido, de novo, as feiras parecem sair à frente na concorrência com as bienais, pois muitas vezes acabam expondo obras inéditas que resguardam seu futuro encaixotadas no "estoque" de uma coleção e/ou investidor privado.

\section{CONSIDERAÇÕES FINAIS: A DIALÉTICA DO CIRCUITO E O PODER DE FOGO DA ARTE}

Do ponto de vista do mercado, as escalas de precificação e valorização da arte contemporânea se fazem em graus crescentes - do artista à galeria, da galeria à feira, da feira ao leilão. Quanto mais o objeto de arte circula de volta ao mercado, mais se requerem conhecimentos e estratégias muito próximos à economia do mercado de ativos - taxas de juros, bolhas especulativas e assim por diante. As estratégias para incrementaros negócios da mercadoria "arte" passam necessariamente pelo seu caráter "especial”, cuja exclusividade lhe atribui o poder de extrair renda monopolista.

De outro lado do circuito, o artista, o crítico, o curador, o historiador, a instituição, o museu - aqueles que não pertencem diretamente 
[44] Fialho, Ana Leticia. "Expansão do mercado de arte no Brasil: oportunidades e desafios", op. cit., p. 38 .

[45] Moraes, Angélica de. "Valorações do transitório", op. cit., p. 92. ao grupo dos UNWI - colaboram de maneira direta e primordial para o incremento dos valores negociados. Tal como enuncia Fialho, "Antes de mais nada,é o capital simbólico acumulado pelo artista que sustenta e alavanca o preço no mercado" 44 . O marchand, de certa forma, opera nos dois lados da moeda, pois o trabalho da galeria consiste igualmente em fomentar a valorização simbólica, cumprindo uma função cultural em parceria com o seu artista representado.

A valorização em escala passa, então, do artista (obras e currículo) à apresentação e/ou à representação de seus trabalhos em galerias, seguindo o desempenho das obras nas feiras, podendo ser exploradas com mais vigor no mercado secundário dos leilões. O crivo institucional viria a colaborar por meio das exposições culturais temporárias, das bienais afora e da presença em acervos museológicos, entre outras dimensões.

No Brasil, tal como vem ocorrendo com a esfera institucional já mencionada, a explosão do mercado de arte dos últimos anos não tem sido acompanhada de um fortalecimento da reflexão (crítica) em proporções equivalentes. Um dos sinais dos tempos é o desinteresse das galeristas em incluir nos portfólios de seus artistas textos que possam elucidar e/ou instigar a fruição do trabalho de arte - e assim fomentar igualmente o interesse do colecionador pela compra. A chancela das participações em determinadas exposições e em determinados acervos parece mais eficiente.

Sob a égide do capitalismo financeiro, será que a dimensão da construção do pensamento crítico e da reflexão dentro do circuito das artes visuais não é suficientemente capaz de atribuir o valor simbólico na mesma velocidade que o mercado? Para Moraes, a crítica implica igualmente um tempo de trabalho similar ao tempo de produção da obra ${ }^{45}$, e esse tempo parece não alcançar a velocidade das engrenagens frenéticas do mercado.

Será que o lugar da crítica, assim, foi posto de lado, na dimensão paralela sob o rótulo "alternativo" e "independente"? Seria a crítica capaz de realizar suas atividades de forma autônoma, desinteressada, exclusivamente fora do mercado? Ou será que a arte e sua dimensão reflexiva são capazes de persuadir o próprio sistema capitalista de trocas simbólicas e produzir conhecimento dentro dele?

Quando Rivitti diz que os espaços independentes servem inclusive como uma experiência formadora para um artista maduro comercialmente, prefiro acreditar que essas duas instâncias devem conviver mutuamente, sem separar gerações, e que os artistas devem nutrir-se de ambas, infinitamente. O mais saudável seria o circuito da arte contemporânea operar com as duas instâncias concomitantemente - como mercadoria e como pensamento crítico, sem prejuízo de nenhuma delas - e os espaços institucionais e alternativos coexistirem 
em constante dialética - pois são mutuamente formadores, sem ser um a preparação para o outro.

Vale lembrar, para concluir, a obra de Rubens Mano exposta na Galeria Milan em 2011; nela, o artista inscreve sobre uma espécie de lápide negra a frase apócrifa "artista sem galeria é artista morto".

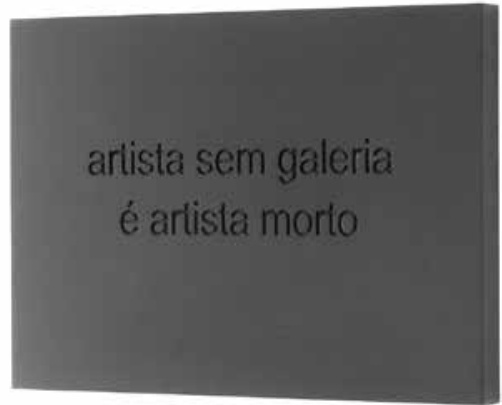

Recebido para publicação em 29 de abril de 2015.

\section{NOVOS ESTUDOS}

CEBRAP

101, março 2015

pp. 117-132

Rubens Mano.s/título [sem galeria], 2011. Placa de corian, $50 \times 76$ ×3,6 cm.

TATIANA SAMPAio FerRaz é pesquisadora, com formação em Artes Plásticas pelo Instituto de Artes da Unesp (2000) e em Arquitetura e Urbanismo pela Escola da Cidade (2007). É mestre em História da Arte pela ECA-USP (2006) e atualmente é doutoranda do Programa de Pós-Graduação em História e Fundamentos da Arquitetura e do Urbanismo da FAU-USP. 